\title{
Front Matter: Volume 9299
}

, "Front Matter: Volume 9299," Proc. SPIE 9299, International Symposium on Optoelectronic Technology and Application 2014: Optical Remote Sensing Technology and Applications, 929901 (26 November 2014); doi: $10.1117 / 12.2178557$

SDIE Event: International Symposium on Optoelectronic Technology and SPIE. Application 2014, 2014, Beijing, China 


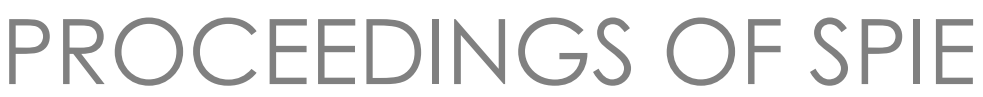

\title{
International Symposium on Optoelectronic Technology and Application 2014 \\ Optical Remote Sensing Technology and Applications
}

\author{
Anatoli G. Borovoi \\ Dong Liu \\ Editors
}

\section{3-15 May 2014 \\ Beijing, China}

Organized by

Photoelectronic Technology Committee, Chinese Society of Astronautics (China)

Sponsored by

Chinese Society of Astronautics (China)

China High-tech Industrialization Association (China)

Technical Cosponsor and Publisher

SPIE

Volume 9299 
The papers included in this volume were part of the technical conference cited on the cover and title page. Papers were selected and subject to review by the editors and conference program committee. Some conference presentations may not be available for publication. The papers published in these proceedings reflect the work and thoughts of the authors and are published herein as submitted. The publisher is not responsible for the validity of the information or for any outcomes resulting from reliance thereon.

Please use the following format to cite material from this book:

Author(s), "Title of Paper," in International Symposium on Optoelectronic Technology and Application 2014: Optical Remote Sensing Technology and Applications, edited by Anatoli G. Borovoi, Dong Liu, Proceedings of SPIE Vol. 9299 (SPIE, Bellingham, WA, 2014) Article CID Number.

ISSN: 0277-786X

ISBN: 9781628413854

Published by

SPIE

P.O. Box 10, Bellingham, Washington 98227-0010 USA

Telephone +1 3606763290 (Pacific Time) · Fax +1 3606471445

SPIE.org

Copyright (c) 2014, Society of Photo-Optical Instrumentation Engineers.

Copying of material in this book for internal or personal use, or for the internal or personal use of specific clients, beyond the fair use provisions granted by the U.S. Copyright Law is authorized by SPIE subject to payment of copying fees. The Transactional Reporting Service base fee for this volume is $\$ 18.00$ per article (or portion thereof), which should be paid directly to the Copyright Clearance Center (CCC), 222 Rosewood Drive, Danvers, MA 01923. Payment may also be made electronically through CCC Online at copyright.com. Other copying for republication, resale, advertising or promotion, or any form of systematic or multiple reproduction of any material in this book is prohibited except with permission in writing from the publisher. The CCC fee code is 0277-786X/14/\$18.00.

Printed in the United States of America.

Publication of record for individual papers is online in the SPIE Digital Library.

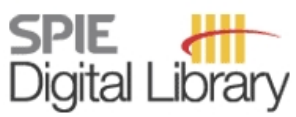

SPIEDigitallibrary.org

Paper Numbering: Proceedings of SPIE follow an e-First publication model, with papers published first online and then in print and on CD-ROM. Papers are published as they are submitted and meet publication criteria. A unique, consistent, permanent citation identifier (CID) number is assigned to each article at the time of the first publication. Utilization of CIDs allows articles to be fully citable as soon as they are published online, and connects the same identifier to all online, print, and electronic versions of the publication. SPIE uses a six-digit CID article numbering system in which:

- The first four digits correspond to the SPIE volume number.

- The last two digits indicate publication order within the volume using a Base 36 numbering system employing both numerals and letters. These two-number sets start with $00,01,02,03,04$, $05,06,07,08,09,0 A, 0 B \ldots$. 0Z, followed by 10-1Z, 20-2Z, etc.

The CID number appears on each page of the manuscript. The complete citation is used on the first page, and an abbreviated version on subsequent pages. Numbers in the index correspond to the last two digits of the six-digit CID number. 


\title{
Contents
}

\author{
vii Authors \\ ix Symposium Committees \\ xii Conference Committee \\ $\mathrm{xv}$ Introduction
}

OPTICAL REMOTE SENSING TECHNOLOGY AND APPLICATIONS

929902 Assessing the capabilities of hyperspectral remote sensing to map oil films on waters [9299-2]

929903 Development of sea ice monitoring with aerial remote sensing technology [9299-3]

929904 The coastline remote sensing survey for Zhao Shu Island in Xisha Islands based on WorldView-2 [9299-6]

929905 An analysis on effecting factors of ultra-violet imaging appliance in corona discharge [9299-7]

929906 Relative radiometric calibration method based on linear CCD imaging the same region of non-uniform scene [9299-8]

929907 The design and study of a new micropulse Lidar [9299-13]

929908 Design of transient light signal simulator based on FPGA [9299-14]

929909 Laser radar range profile, Doppler spectra and range resolved Doppler imaging technologies for the target recognition [9299-16]

9299 OA Design of a multi-spectral TDICCD focal plane imaging and processing system based on FPGA [9299-17]

9299 OB Lifetime radiometric calibration of HJ-1A/B CCD sensor using Dunhuang Gobi site [9299-18]

9299 OC Telecentric system with large-field for surveillance and measuring camera in space station [9299-19]

9299 OD During air cool process aerosol absorption detection with photothermal interferometry [9299-20]

9299 OE The vegetation coverage dynamics due to geohazards after the 2008 earthquake in Wenchuan [9299-21] 
92990F Typhoon center location algorithm based on fractal feature and gradient of infrared satellite cloud image [9299-25]

92990G Multiscale snapshot imaging spectrometer with large FOV and fast speed [9299-26]

92990H An infrared remote sensor with high integration and multi-spectral bands [9299-27]

9299 0l A data preprocessing method based on multi-threshold [9299-28]

9299 0J An integrated GIS application system for soil moisture data assimilation [9299-29]

9299 OK Design and realization of data acquisition system of FTS based on FPGA [9299-30]

$9299 \mathrm{OL}$ Observations of atmospheric trace gases by MAX-DOAS in the coastal boundary layer over Jiaozhou Bay [9299-33]

9299 OM Sun glitter imaging analysis of submarine sand waves in HJ-1A/B satellite CCD images [9299-35]

9299 ON Research on influence of space-borne stereo mapping camera's time synchronization precision on attitude angle errors [9299-37]

929900 Investigation on navigation patterns of inertial/celestial integrated systems [9299-38]

9299 OP Quantum-inspired remote sensing image denoising with double density dual-tree complex wavelet transform [9299-39]

92990 Spatial decision supporting for winter wheat irrigation and fertilizer optimizing in North China Plain [9299-41]

9299 OR Online sparse representation for remote sensing compressed-sensed video sampling [9299-42]

9299 OS Retrieval and validation of the true leaf area index using MODIS data [9299-43]

9299 OT CS-based infrared remote sensing video reconstruction with a linearized Bregman error iteration algorithm for 11 -regularized minimization [9299-45]

9299 OU Radiometric quality evaluation of ZY-02C satellite panchromatic image [9299-46]

9299 OV A study to measure optical properties of waters by oceanographic lidar with variable field-of-view [9299-47]

9299 OW Parameters inversing of polarized bidirectional reflectance distribution function model for target rough surface [9299-53]

9299 0X Towards aerial natural gas leak detection system based on TDLAS [9299-54]

9299 OY An integrated method of measuring wave-front aberrations and optical axis jitters of space camera [9299-58] 
$9299 \mathrm{OZ}$ The research of remote sensing in karst collapse remote sense based on airborne LiDAR system: taking Meitanba mining area in Hunan Province as an example [9299-59]

929910 Lidar signal de-noising by singular value decomposition [9299-61]

929911 Study of modified band selection methods of hyperspectral image based on optimum index factor [9299-64]

929912 Dynamic monitoring of vegetation coverage change in Lu County based on TM/OLI-NDVI [9299-66]

929913 Snow cover monitoring model and change over both time and space in pastoral area of northern China [9299-68]

929914 Modeling and validation of spectral BRDF on material surface of space target [9299-69]

929915 A precise laboratory goniometer system to collect spectral BRDF data of materials [9299-70]

929916 Development of dual-wavelength Mie polarization Raman lidar for aerosol and cloud vertical structure probing [9299-71]

929917 Development of semi-sphere field-of-view sun sensor integrated with multiple linear CMOS image sensor [9299-72]

929918 Study on river segmentation and bridge recognition for SAR image based on FSVM [9299-73]

929919 Military reconnaissance application of high-resolution optical satellite remote sensing [9299-74]

92991 A Study on the effects of the space environment on laser transmission characteristics [9299-76]

9299 1B A study on correlation between national imagery interpretability rating scale and discrimination probability [9299-77]

9299 1C Establishing monitoring model of Haze event with multi-satellite data and application-a case: Yangtze River Delta [9299-78]

9299 1D Application of the polarization Raman Mie lidar system to monitor the particulate matter and water vapor in the aerosol pollution and haze episodes [9299-80]

9299 1E System calibration of Stokes imaging polarimeter using Fourier series analysis [9299-218] 
Proc. of SPIE Vol. $9299929901-6$

Downloaded From: https://www.spiedigitallibrary.org/conference-proceedings-of-spie on 26 Apr 2023 Terms of Use: https://www.spiedigitallibrary.org/terms-of-use 


\section{Authors}

Numbers in the index correspond to the last two digits of the six-digit citation identifier (CID) article numbering system used in Proceedings of SPIE. The first four digits reflect the volume number. Base 36 numbering is employed for the last two digits and indicates the order of articles within the volume. Numbers start with 00, 01, 02, 03, 04, 05, 06, 07, 08, 09, OA, OB...0Z, followed by 10-1Z, 20-2Z, etc.

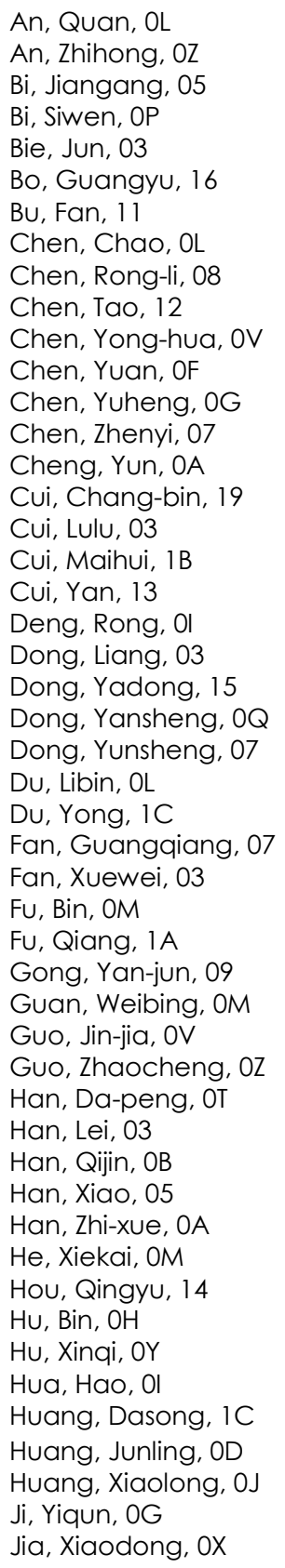

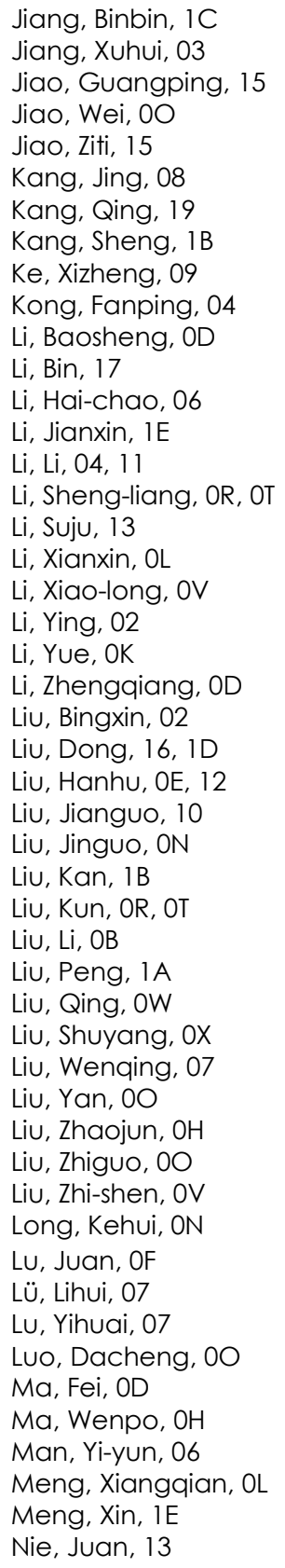

\section{Downloaded From: https://www.spiedigitallibrary.org/conference-proceedings-of-spie on 26 Apr 2023


Qi, Shaoshuai, 07

Qu, Junle, OL

Sasian, Jose, OG

Shang, Zhen, ID

Shao, Jie, 16

Shen, Runping, 0J

Shen, Zhi-qiang, 19

Shi, Chunxiang, OJ

Su, Bida, Ol

Sun, Ke, OU

Sun, Qianqian, OY

Sun, Tao, 18

Tang, Shaofan, $\mathrm{OH}$

Tang, Tian-jin, OC

Teng, Yang, 09

Tong, Jing-bo, OC

Tong, Shoufen, $1 \mathrm{~A}$

Wang, Aichun, OB

Wang, Bangxin, 16, 1D

Wang, Di, OJ

Wang, Dong, OA

Wang, Haiying, OK

Wang, Hao, $\mathrm{OZ}$

Wang, Hong, 08

Wang, Huanxue, 10

Wang, Hui, 18

Wang, Humei, OY

Wang, Jie, OR, OT

Wang, Jie, 15

Wang, Jingfeng, 01

Wang, Ming-Jun, 09

Wang, Ping, 13

Wang, Qiuyan, 00

Wang, Shitao, OY

Wang, Shuhua, 0

Wang, Xiufen, OL

Wang, Yicheng, OD

Wang, Yingjian, 16, 1D

Wang, Zhangjun, OL

Wang, Zheng-gang, 19

Wang, Zhenzhu, 16

Wei, Shuhui, OP

Wen, Qi, 13

Wu, Chengxuan, OL

Wu, Decheng, 16

Wu, Fang, $\mathrm{OZ}$

Wu, Pengfei, 09

Wu, Xingxing, ON

Xie, Chenbo, 16, 1D

$X U$, Jianming, $O E$

$\mathrm{XU}$, Limei, OD

Xun, Yi-jia, 19

Yang, Di, OW

Yang, $\mathrm{HaO}, \mathrm{OQ}$

Yang, Kang, $O M$

Yang, Lei, OU

Yang, Ning, 05

Yang, Suhui, Ol

Yang, Xiaodong, $0 Q$

Yin, Dong, 18
YU, Haiyang, $O Q$

Yuan, Shuai, 05

Yuan, Wen, OS

Zeng, Chang-e, OW

Zeng, Sen, OE, 12

Zhai, Guo-fang, OA

Zhan, Yong-hong, OW

Zhang, Boyan, ON

Zhang, Changjiang, OF

Zhang, Fan, 17

Zhang, $\mathrm{Hu}, 15$

Zhang, Huaguo, OM

Zhang, Huili, 14

Zhang, Jing-jing, OA

Zhang, Li, OR, OT

Zhang, Lisha, $\mathrm{OH}$

Zhang, Peng, $1 \mathrm{~A}$

Zhang, Tianshu, 07, 10

Zhang, Wei, 13

Zhang, Wei, 14

Zhang, Xiaoyu, 1C

Zhang, Xuewen, OB

Zhang, Ying, OP

Zhang, Yumei, 1E

Zhang, Zhizhou, OT

Zhao, Chao-fang, OV

Zhao, Fengfan, OU

Zhao, Ming, 1D

Zhao, Yao-kun, 17

Zhi, Xiyang, 14

Zhong, Chang, 04, 11

Zhong, Hua, Ol

Zhong, Zhiqing, 16, 1D

Zhou, Haijin, OL

Zhou, Huaide, ON

Zhou, Jianjun, 1B

Zhou, Jiankang, OG

Zhou, Tao, OX

Zhu, Gaolong, OS

Zhu, Rihong, $1 \mathrm{E}$

Zhu, Xueyuan, 02 


\title{
Symposium Committees
}

\author{
Symposium Chairs
}

Guofan Jin, Tsinghua University (China)

Songlin Zhuang, University of Shanghai for Science and Technology (China)

\section{Conference Committee}

Bingheng Lu, Xi'an Jiaotong University (China)

Byoungho Lee, Seoul National University (Republic of Korea)

Daren Lv, Institute of Atmospheric Physics (China)

David Webb, Aston University (United Kingdom)

Dianyuan Fan, Shanghai Institute of Optics and Fine Mechanics (China)

Feng Zhang, Academy of Chinese Aerospace Science and Industry Feihang Technology (China)

Gaurav Sharma, University of Rochester (United States)

Guangjun Zhang, Beihang University (China)

Huitao Fan, Luoyang Optoelectro Technology Development Center (China)

Huixing Gong, Shanghai Institute of Technical Physics (China)

Jannick Rolland, University of Rochester (United States) and LighTopTech Corporation (United States)

Jianquan Yao, Tianjin University (China)

Jiaqi Wang, Changchun Institute of Optics, Fine Mechanics and Physics (China)

Jingshan Jiang, Center for Space Science and Applied Research (China)

Junhao Chu, Shanghai Institute of Technical Physics (China)

Lijun Wang, Changchun Institute of Optics, Fine Mechanics and Physics (China)

Lin Li, Laser Processing Research Centre, The University of Manchester (United Kingdom)

Liwei Zhou, Beijing Institute of Technology (China)

Ming C. Leu, Missouri University of Science and Technology (United States)

Norbert Kaiser, Fraunhofer Institute for Applied Optics and Precision Engineering (Germany)

Qifeng Yu, National University of Defense Technology (China)

Qingxi Tong, The Institute of Remote Sensing and Digital Earth (China)

Shouhuan Zhou, North China Research Institute of Electro-optics (China) 
Tianchu Li, National Institute of Metrology (China)

Ting-Chung Poon, Virginia Polytechnic Institute and State University (United States)

Wei Wang, Beijing Institute of Aerospace Control Devices (China)

Zuyan Xu, The Technical Institute of Physics and Chemistry (China)

Program Committee

Songlin Zhuang, Chair, University of Shanghai for Science and Technology (China)

Huaming Wang, Co-chair, Beihang University (China)

Huikai Xie, Co-chair, University of Florida (United States)

Jannick Rolland, Co-chair, University of Rochester (United States)

Jürgen Czarske, Co-chair, Technische Universität Dresden

(Germany)

Yongtian Wang, Co-chair, Beijing Institute of Technology (China)

Anatoli G. Borovoi, V.E. Zuev Institute of Atmospheric Optics

(Russian Federation)

Bincheng Li, Institute of Optics and Electronics (China)

Binghen Lu, Xi'an JiaoTong University (China)

Byoungho Lee, Seoul National University (Republic of Korea)

Changxiang Yan, Changchun Institute of Optics, Fine Mechanics and Physics (China)

Dae Wook Kim, The University of Arizona (United States)

David Webb, Aston University (United Kingdom)

Dawei Zhang, University of Shanghai for Science and Technology (China)

Dong Liu, Anhui Institute of Optics and Fine Mechanics (China)

Fugen Zhou, Beijing University of Aeronautics and Astronautics (China)

Gaurav Sharma, University of Rochester (United States)

Geert Verhaeghe, Faurecia Autositze GmbH (Germany)

Guangya Zhou, National University of Singapore (Singapore)

Haimei Gong, Shanghai Institute of Technical Physics (China)

Jin Lu, Tianjin Jinhang Institute of Technical Physics (China)

Jun Zhou, Shanghai Institute of Optics and Fine Mechanics (China)

Kai Cheng, Brunel University (United Kingdom)

Ligong Zheng, Changchun Institute of Optics Fine Mechanics and Physics (China)

Lijun Wang, Changchun Institute of Optics, Fine Mechanics and Physics, (China)

Lin Li, Laser Processing Research Centre, The University of Manchester (United Kingdom)

Ming C. Leu, Missouri University of Science and Technology (United States)

Minlin Zhong, Tsinghua University (China)

Mircea Guina, Tampere University of Technology (Finland) 
Norbert Kaiser, Fraunhofer Institute for Applied Optics and Precision Engineering (Germany)

Pu Wang, Beijing University of Technology (China)

Roland Winston, University of California (United States)

Rongbing W. B. Lee, The Hong Kong Polytechnic University (Hong Kong, China)

Shulian Zhang, Tsinghua University (China)

Ting-Chung Poon, Virginia Polytechnic Institute and State University (United States)

Wei Wang, Beijing Institute of Aerospace Control Devices (China)

Wenli Ma, The Institute of Optics and Electronics (China)

Yi Luo, Tsinghua University (China)

Yiqin Ji, Tianjin Jinhang Institute of Technical Physics (China)

Yong Bi, Academy of Opto-electronics (China)

Yong Cheng, Wuhan Ordnance Non-Commissioned Officers Academy (China)

Yongnian Yan, Jiangsu YONGNIAN Laser Forming Technology Company, Ltd. (China)

Zhichuan Niu, Institute of Semiconductors (China) 
Proc. of SPIE Vol. $9299929901-12$

Downloaded From: https://www.spiedigitallibrary.org/conference-proceedings-of-spie on 26 Apr 2023 Terms of Use: https://www.spiedigitallibrary.org/terms-of-use 


\section{Conference Committee}

Conference Chairs

Anatoli G. Borovoi, Institute of Atmospheric Optics

(Russian Federation)

Dong Liu, Anhui Institute of Optics and Fine Mechanics (China)

Proc. of SPIE Vol. $9299929901-13$

Downloaded From: https://www.spiedigitallibrary.org/conference-proceedings-of-spie on 26 Apr 2023 Terms of Use: https://www.spiedigitallibrary.org/terms-of-use 
Proc. of SPIE Vol. 9299 929901-14

Downloaded From: https://www.spiedigitallibrary.org/conference-proceedings-of-spie on 26 Apr 2023 Terms of Use: https://www.spiedigitallibrary.org/terms-of-use 


\section{Introduction}

We had the great honor of organizing the International Symposium on Optoelectronic Technology and Application 2014 (IPTA 2014) in Beijing. It was truly a great pleasure for us to greet nearly 1,000 participants from many different countries attending IPTA 2014! We firmly believe that the symposium will become an important international event in the field of photoelectronic technology.

IPTA 2014 was sponsored by Chinese Society of Astronautics (CSA) and China Hightech Industrialization Association, technically co-sponsored by SPIE, and organized by Photoelectronic Technology Committee, Chinese Society of Astronautics. 27 cooperating organizations supported the conference. There were nearly 600 papers accepted for presentation at IPTA 2014, contributed by over 1078 authors from more than 10 countries, including United States, United Kingdom, Germany, France, Norway, Australia, Canada, Japan, Korea, Russia, and China. We had six plenary speeches and 228 well-known scientists and experts, from both home and abroad to give invited talks at different sessions.

The purpose of IPTA 2014 was to provide a forum for the participants to report and review innovative ideas, with up-to-date progress and developments, and discuss the novel approaches to application in the field of photoelectronic technology. We sincerely hope that the research and development in the optical and photoelectronic fields will be promoted, and international cooperation sharing the common interest will be enhanced.

On behalf the Organization Committee of IPTA 2014, we would like to heartily thank our sponsors and cooperating organizations for all they have done for the conference. We would also like to thank the authors for their contribution to the proceedings; the participants and friends of IPTA 2014, for their interest and efforts in helping us to make the symposium possible; and the Program Committee for their effective work and valuable advice, especially the IPTA 2014 Secretariat and the SPIE staff, for their tireless efforts and outstanding services in preparing the conference and publishing the Proceedings.

\section{Guofan Jin \\ Songlin Zhuang \\ IPTA 2014 Symposium Committee Chairs}


Proc. of SPIE Vol. 9299 929901-16

Downloaded From: https://www.spiedigitallibrary.org/conference-proceedings-of-spie on 26 Apr 2023 Terms of Use: https://www.spiedigitallibrary.org/terms-of-use 